\title{
High Immunoexpression of COX-2 as a Metastatic Risk Factor in ccRCC without PD-LI Involvement
}

\author{
Sri Suryanti \\ Hasrayati Agustina \\ Afiati Aziz \\ Herry Yulianti \\ Bethy Suryawathy \\ Lestari Putri
}

Department of Anatomical Pathology, Faculty of Medicine, Universitas Padjadjaran/Dr. Hasan Sadikin Hospital, Bandung, Indonesia
Correspondence: Lestari Putri

Department of Anatomical Pathology, Faculty of Medicine, Universitas Padjadjaran/

Dr. Hasan Sadikin General Hospital, Jl.

Pasteur No. 38, Bandung, 40161, Indonesia

Tel +6282217755916

Fax +62222031447

Email lestariputri_dr@yahoo.com
Introduction: Clear cell renal cell carcinoma (ccRCC) is the most lethal type of malignancy of the urinary tract system as it is resistant to chemotherapy and radiation and has a survival rate of less than $5 \%$ in cases of metastasis. Inflammation plays an essential role in the metastasis of ccRCC. Cyclooxygenase- $2(\mathrm{COX}-2)$ is an inflammatory protein that affects the processes of carcinogenesis, invasion, migration, metastasis, and angiogenesis. COX-2 can modulate programmed death ligand-1 (PD-L1) expression and play a role in immune evasion, meaning that tumor cells are able to escape the body's immune response and more easily metastasize.

Purpose: This study aims to determine the role of COX-2 and PD-L1 in the occurrence of ccRCC metastases.

Materials and Methods: This study is an observational analytical study, which employed a cross-sectional approach to examine the paraffin block samples of $40 \mathrm{ccRCC}$ cases from Dr. Hasan Sadikin Hospital Bandung, Indonesia, between 2014 and 2021. Immunoexpression was measured using immunohistochemical staining for COX-2 in tumor cells and for PD-L1 in immune cells. PD-L1 calculation was measured using Qupath 0.2.3. digital software. Metastatic data were obtained using radiological imaging and pathological examinations. Meanwhile, the data were analyzed using the chi-square test for COX-2 and Fischer's exact test for PD-L1.

Results: The research results revealed a significant association between COX-2 and the occurrence of metastases in ccRCC $(\mathrm{p}=0.001)$ with a prevalence odds ratio of 10.28 . Positive PD-L1 immunoexpression of the immune cells $(\geq 1 \%)$ was found in $14 \%$ (3/ $21)$ of the metastatic group and $5 \%(1 / 19)$ of the non-metastatic group $(p=0.607)$. There was no association between COX-2 and PD-L1 immunoexpression $(p=0.278)$.

Conclusion: This study shows that metastases in ccRCC patients are ten times as likely to be associated with high COX-2 immunoexpression than low COX-2 immunoexpression. COX-2 plays a role in the process of ccRCC metastasis without PD-L1 involvement.

Keywords: clear cell renal cell carcinoma, cyclooxygenase-2, metastasis, programmed death ligand-1

\section{Introduction}

Clear cell Renal Cell Carcinoma (ccRCC) is the main histological subtype of renal epithelial malignancies, and originates in proximal tubular epithelial cells, with an increasing incidence worldwide. ${ }^{1,2}$ Metastasis is the cause of $90 \%$ of deaths in patients with ccRCC, ${ }^{2}$ with ccRCC metastases often not exhibiting specific clinical symptoms or laboratory results. In some cases, detection can be delayed until late in 
the latency period following surgical removal of the tumor. ${ }^{3}$ Therefore, early detection of potential metastases is imperative to provide appropriate treatment for a better prognosis.

Clear cell RCC are known to be resistant to chemotherapy and radiotherapy, making it easier for tumor cells to become aggressive and metastasize. One of the main biological characteristics of ccRCC behind this phenomenon is that ccRCC tumors are highly vascularized. The main pathogenesis of ccRCC is the inactivation of the key oxygen-sensing gene, the Von Hippel Lindau (VHL) gene. Inactivation of the VHL gene causes an accumulation of hypoxia-inducible factor-1 $\alpha$ (HIF-1 $\alpha$ ), which affects the tumor microenvironment (TME) and thus potentially supporting the tumor's progression to invasion and metastasis. ${ }^{4}$ Invasion and metastasis is a complex process, involving interactions between tumor cells, the extracellular matrix (ECM), adhesion molecules, and blood vessels, which act as a crucial point-of-access for tumor cells to spread to the site of metastasis. The interaction process is mediated by inflammatory cytokines, which are the primary mediators of metastasis. ${ }^{5}$ Cytokines from tumor cells are produced through inflammation-related pathways, including the VHL pathway, mammalian target of rapamycin (mTOR) pathway, signal transducer and activator of transcription (STAT3) pathway, and tumor necrosis factor (TNF) pathway. All inflammation-related pathways can stimulate cytokines from tumor cells, which may lead to the induction of COX-2 overexpression. The VHL pathway is the main inflammation-related pathway for ccRCC. $^{4,5}$

COX-2 is a pleiotropic enzyme produced by various cancer cells. COX-2 plays a role in carcinogenesis and the resistance of cancer cells to chemotherapy and radiotherapy. ${ }^{6}$ Additionally, COX-2 also affects angiogenesis, which is essential for successful metastasis of ccRCC. ${ }^{7}$ COX-2 modulates the expression of programmed death ligand-1 (PD-L1) on immune cells around the tumor, which are a main component of the immune checkpoint. ${ }^{8}$ PD-L1 is expressed by tumor cells and immune cells located around the tumor. PD-L1 produced by immune cells are a result of adapted immune resistance influenced by tumor immunogenicity, thus determining the clinical efficacy of anti-PD-1/PD-L1 therapy. ${ }^{9,10}$

Antiangiogenic therapy for patients with metastatic ccRCC is costly and resistance has been reported. ${ }^{11}$ COX-2 inhibitors are economical anti-inflammatory and antiangiogenic, and are widely used in breast and colorectal carcinomas. ${ }^{12,13}$ Anti-PD-L1 therapy has been used in a wide range of countries. ${ }^{14}$ However, studies have revealed that PD-L1 expression in ccRCC varies greatly. Numerous studies on the association between COX-2 and PD-L1 immunoexpression in melanomas, ${ }^{8}$ urothelial carcinomas, ${ }^{15}$ and breast carcinomas have been conducted. ${ }^{16,17}$ Despite this, similar studies on ccRCC are limited.

This study aims to analyze the respective association between COX-2 and PD-L1 immunoexpression in the occurence of metastases in ccRCC. The research results will assist in explaining the role of inflammation in the pathogenesis of metastatic ccRCC, and may be used as a theoretical basis for the use of COX-2 inhibitors and PDL1 as supportive therapies.

\section{Materials and Methods}

This study employed an analytical observational research design using cross-sectional methods. Sampling was conducted using the consecutive sampling technique, and taken from the paraffin blocks of patients at Dr. Hasan Sadikin Hospital in Bandung, Indonesia, between January 2014 and May 2021, which met the inclusion and exclusion criteria. Inclusion criteria included the paraffin blocks of patients who had undergone radical nephrectomy surgery and been diagnosed with histopathologic ccRCC, with no missing data. Exclusion criteria included paraffin blocks obtained through biopsies, or with an insufficient tumor mass.

\section{Ethical Clearance}

The study's use of subjects and patients' clinical data was approved by the board of the Medical and Health Research Ethics Committee at Dr. Hasan Sadikin Hospital in Bandung, Indonesia, on May 312021 (Reference No.: 463/UN6.KEP/EC/2021), in compliance with the provisions set out in the Declaration of Helsinki. Confidentiality of the patients' data was ensured by withholding the patients' personal data.

\section{Clinicopathological Parameters}

The clinicopathological parameters included analyses of age, sex, and kidney laterality; nuclear grading based on criteria from the International Society of Urological Pathology (ISUP); rhabdoid and sarcomatoid differentiation; stages; and metastasis. Metastatic data were obtained using radiological examinations, or histopathological or cytopathological examinations from a tissue biopsy or 
fine-needle aspiration biopsy. Subjects included patients with metastatic ccRCC diagnosed either at the time of nephrectomy or after the latency period from 2014 until the commencement of the research in 2021.

\section{Immunohistochemical Evaluation and Staining}

Immunohistochemical staining of all samples was conducted in accordance with the streptavidin-biotin immunoperoxidase complex label method using One-step Neopoly Detection Kits (Biogear Scientific, BioVentures, Inc., Iowa, USA). Paraffin blocks were cut to $4 \mu \mathrm{m}$ thickness, then cleaned using xylol and rehydrated using an alcohol solution. The antigens were obtained using a decloaking device for 45-60 minutes at 98 degrees Celsius.

Immunohistochemical staining was conducted using COX-2 primary antibodies (mouse monoclonal antihuman cyclooxygenase-2 clone 3D4 (BZ-089830F-AM) Bioenzy, Shanghai, China) with a dilution of 1: 400 , overnight at 4 degrees Celsius, and PD-L1 primary antibodies (rabbit monoclonal antibody SP142 Paint \#ab228462 (Abcam, Cambridge, UK) with a dilution of 1: 300 .

COX-2 immunoexpression was assessed by measuring the brown staining in the cytoplasm of the tumor cells in 10 fields of view, and then taking the average for each field of view. Values $\geq 10 \%$ were considered high, while those $<10 \%$ were classified as low. ${ }^{7}$

PD-L1 immunoexpression was quantitatively assessed by calculating the total number of stained immune cells within the tumor, which frequently exhibited dark brown punctuate, circumferential, or linear coloring, using Qupath 0.2.3 digital software (Queen's University of Belfast, Northern Ireland, UK). ${ }^{18}$ The majority of the immune cells were morphologically consistent with lymphocytes, dendritic cells, macrophages, and granulocytes. Tumor cells and immune cells are differentiated by their morphology. ccRCC Tumor cells are typically more than twice as large as immune cells. They also have a clear cytoplasm and distinct membrane. ${ }^{2}$ The denominator was the total number of all tumor cells. Values $\geq 1 \%$ were classified as positive, while those $<1 \%$ were categorized as negative. ${ }^{8}$ The assessment was conducted by three anatomical pathology specialists before being informed of the patients' characteristics. All discrepancies found were re-evaluated, preferencing the dominant result.

\section{Statistical Data Analysis}

This study is an observational analysis adopting a crosssectional method. COX-2 were statistically analyzed using the Chi-square test, while PD-L1 were statistically analyzed using Fischer's exact test. A p-value $<0.05$ was considered significant. The data were tabulated and then processed using Statistical Package for the Social Science (SPSS) software (version 22.0, IBM SPSS Corp., Armonk, NY, USA). Risk estimates were statistically analyzed using the Prevalence Odds Ratio (POR) function in SPSS. POR is the preferred method of measuring association in cross-sectional studies of chronic diseases or studies on long-lasting risk factors. ${ }^{19}$

\section{Results}

\section{Research Subject Characteristics}

A total number of 65 samples were collected from the research subjects. However, only 40 samples met the inclusion and exclusion criteria. The mean age of the patients included as research subjects was 51 years with an age range of $22-80$ years old, $72.5 \%$ of the patients were male and $27.5 \%$ were female, and the nuclear grading of most grade 2 and 3 ISUP was 30/40 (75\%), respectively, with $6 / 40(15 \%)$ rhabdoid differentiation, and 3/40 (7.5\%) sarcomatoid differentiation. Unilateral renal involvement was found in the largest proportion of patients, or $38 / 40$ (95\%). The largest tumor stage encountered was stage 4 in $33(82.5 \%)$ of the patients. Twenty-five (62.5\%) of the patients exhibited high COX-2 immunoexpression, while 15 (37.5\%) exhibited low COX-2 immunoexpression. Positive PD-L1 immunoexpression was found in four of the forty cases $(10 \%)$, while negative PDL1 immunoexpression was found in 36 cases (90\%). Twenty-one cases were metastatic $(52.5 \%)$, consisting of 19 patients who were diagnosed with metastasis at the time of nephrectomy. The other two patients were diagnosed after the latency period. Nineteen $(47.5 \%)$ of the forty cases were non-metastatic. The characteristic of ccRCC patients in dependence of metastasis are presented in Table 1.

\section{Immunoexpression COX-2 and PD-LI}

COX-2 and PD-L1 staining was performed on all samples. The staining results were evaluated based on the distribution of tumor cells stained for COX-2 and immune cells stained for PD-L1. COX-2 and PD-L1 immunoexpression are presented in Figures 1 and 2. 
Table I Research Subject Characteristics

\begin{tabular}{|c|c|c|c|}
\hline \multirow[t]{2}{*}{ Variable } & \multicolumn{2}{|c|}{ Cases } & \multirow[t]{2}{*}{$p$-value } \\
\hline & $\begin{array}{l}\text { Non-Metastatic } \\
\text { ccRCC Group } \\
(\mathrm{N}=19)\end{array}$ & $\begin{array}{l}\text { Metastatic } \\
\text { ccRCC Group } \\
(\mathrm{N}=2 \mathrm{I})\end{array}$ & \\
\hline Age & & & 0.655 \\
\hline Mean \pm Std & $52.26 \pm 13.274$ & $50.33 \pm 13.793$ & \\
\hline Median & 52.00 & 48.00 & \\
\hline $\begin{array}{l}\text { Range (min- } \\
\text { max) }\end{array}$ & $22.00-71.00$ & $28.00-80.00$ & \\
\hline Gender & & & 0.873 \\
\hline Male & $14(74 \%)$ & $15(7 \mid \%)$ & \\
\hline Female & $5(26 \%)$ & $6(29 \%)$ & \\
\hline Laterality & & & 1.000 \\
\hline Unilateral & 18 (94.7\%) & $20(95.2 \%)$ & \\
\hline Bilateral & I (5.3\%) & I (4.8\%) & \\
\hline Nuclear & & & 0.552 \\
\hline Grading ISUP & & & \\
\hline $\mathbf{I}$ & $0(0 \%)$ & $0(0 \%)$ & \\
\hline 2 & 6 (31.6\%) & $10(47.6 \%)$ & \\
\hline 3 & 8 (42.1\%) & $6(28.6 \%)$ & \\
\hline 4 & 5 (26.3\%) & 5 (23.8\%) & \\
\hline Rhabdoid & & & 0.085 \\
\hline Differentiation & & & \\
\hline Yes & 5 (26.3\%) & I (4.8\%) & \\
\hline No & 14 (73.7\%) & $20(95.2 \%)$ & \\
\hline Sarcomatoid & & & 0.233 \\
\hline Differentiation & & & \\
\hline Yes & $0(0 \%)$ & $3(14.3 \%)$ & \\
\hline No & $19(100 \%)$ & 18 (85.7\%) & \\
\hline Stage & & & 0.135 \\
\hline 1 & $0(0 \%)$ & $0(0 \%)$ & \\
\hline 2 & $3(15.8 \%)$ & $0(0 \%)$ & \\
\hline 3 & $2(10.5 \%)$ & $2(9.5 \%)$ & \\
\hline 4 & $14(73.7 \%)$ & 19 (90.5\%) & \\
\hline
\end{tabular}

Abbreviations: ccRCC, Clear Cell Renal Cell Carcinoma; ISUP, International Society of Urological Pathology.

\section{The Association Between COX-2}

\section{Immunoexpression and ccRCC Metastasis}

The association between COX-2 immunoexpression and metastasis is presented in Table 2. Based on Table 2, 18/21 subjects $(85.7 \%)$ in the metastatic group and $7 / 19$ subjects $(36.8 \%)$ in the non-metastatic group had positive COX-2 immune expression ( $\geq 10 \%)$. The statistical analysis revealed a $\mathrm{p}$-value of $0.001 \quad(\mathrm{p}<0.05)$ with a prevalence odds ratio (POR) of 10.28, meaning that there is a significant association between COX-2 immunoexpression and metastasis in ccRCC.

\section{The Association Between PD-LI}

\section{Immunoexpression and ccRCC \\ Metastasis}

The association between PD-L1 immunoexpression and metastasis is described in Table 3. Based on Table 3, 3/18 subjects $(14.3 \%)$ in the metastatic group and $1 / 18$ subjects $(5 \%)$ in the non-metastatic group had positive PD-L1 immunoexpression $(\geq 1 \%)$. Based on the statistical analysis, the $\mathrm{p}$-value was $0.607(\mathrm{p}>0.05)$, meaning that there is no significant association between PD-L1 immunoexpression and metastasis.

\section{The Association Between COX-2 and PD-LI in $\mathrm{CCRCC}$}

The data in Table 4 show that there is no association between COX-2 and PD-L1 immunoexpression ( $\mathrm{p}=0.278$ ).

\section{Discussion}

Inflammation is closely related to ccRCC as it is considered to be an immunogenic tumor. COX-2 is an inflammatory protein that has a function in the carcinogenesis of ccRCC. ${ }^{4}$ This study found high COX-2 immunoexpression in more than $50 \%$ of cases. COX-2 is an enzyme that contributes to the conversion of arachidonic acid into prostaglandins, which is the main metabolite in carcinogenesis. ${ }^{6}$ These findings are consistent with the research of Gipsyianti et al, which revealed high COX-2 immunoexpression in acral melanoma; Szlendak et al on colorectal adenocarcinoma; and Liu et al on renal cell carcinoma. ${ }^{3,20,21}$

The results of the present show a significant association between COX-2 immunoexpression and the occurrence of metastases in ccRCC $(p=0.001)$ with a POR of 10.28 . These results indicate that ccRCC patients with high COX-2 immunoexpression are ten-times as likely to be associated with metastases as ccRCC patients with low COX-2 immunoexpression. This finding correlates with research conducted by Liu et al, which revealed a significant association between COX-2 immunoexpression and metastasis in patients with renal cell carcinoma. ${ }^{3}$ Similar findings were made in a study by Jana et al, which states that one marker of poor prognosis in breast carcinomas is high COX-2 immunoexpression, as it is associated with progression into invasion and metastasis. ${ }^{22}$ The process of metastasis is initiated by invading tumor cells, which break down the basal membrane and the stroma of the connective tissue around the tumor to facilitate the 
A

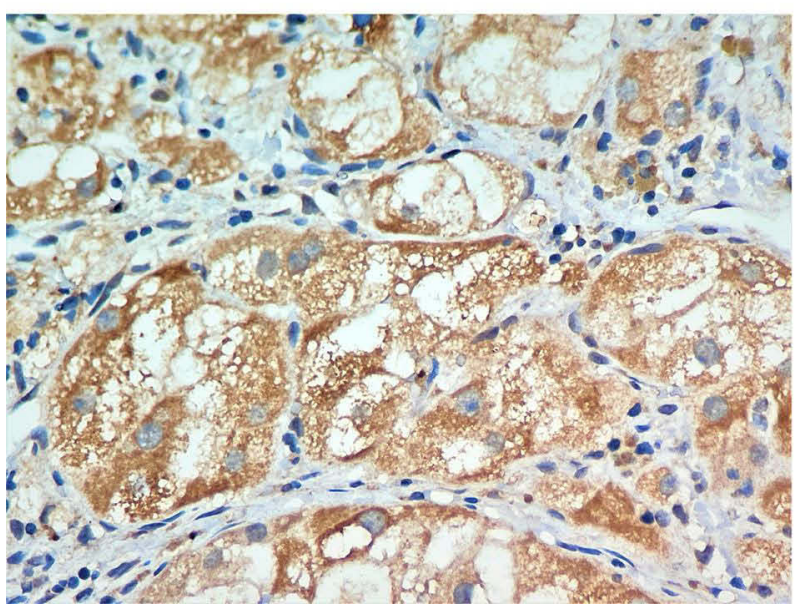

B

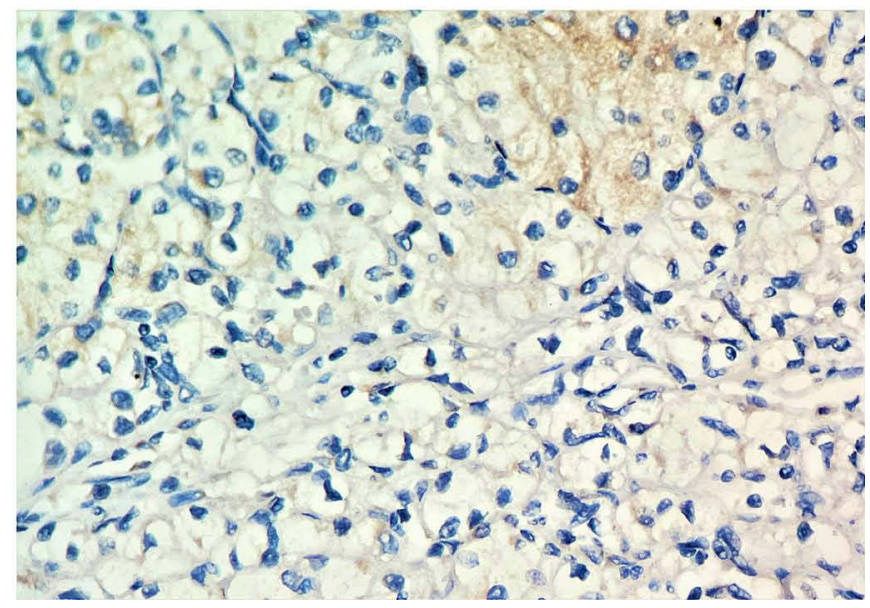

Figure I (A) High COX-2 immunoexpression in clear cell renal cell carcinoma (IHC;400x). (B) Low COX-2 immunoexpression in clear cell renal cell carcinoma (IHC;400x).

migration process. COX-2 plays a vital role in tumor cell invasion and migration by activating matrix metalloproteinases and stimulating extracellular signal-regulated kinases (ERKs)-dependent COX-2-PGE2 pathways. $^{23}$ This process is supported by reactive oxygen species in tumors. ${ }^{23}$ Angiogenesis is an essential process in metastasis; in addition to nourishing tumor cells, angiogenesis also plays a role in forming new blood vessels to support successful metastasis. ${ }^{24} \mathrm{COX}-2$ aids the process of ccRCC angiogenesis by interfering with the regulation of vascular endothelial growth factor (VEGF) expression resulting in VEGF overexpression. COX-2 can also stimulate vascular sprouting, migration, and tube formation; increase endothelial cell survival through BCL2 expression and AKT signaling; activate epidermal growth factor receptormediated angiogenesis; and suppress IL-12 production. $^{25}$

PD-L1 is a transmembrane protein that is bidirectional, which plays a role in immune evasion and the initiation of EMT through sterol regulatory binding protein-1c (SREBP-1c). ${ }^{26}$ In this study, positive PD-L1 immunoexpression for immune cells $(\geq 1 \%)$ was present in $10 \%$ of the sample. However, previous studies have shown that PD-L1 immunoexpression occurred on 10/21 immune cells $(47.6 \%)$. The discrepancy in results is due to differences in sampling methods, for example, multiple site sampling. ${ }^{27}$

Table 3 shows that in the metastatic group, the number of samples with positive PD-L1 immunoexpression was greater than the number from the non-metastatic group. However, there was no significant statistical association between PD-
L1 immunoexpression and the incidence of metastases. This finding is similar to the results obtained by Leite et al, which revealed that PD-L1 immunoexpression was found in only $6 \%$ of metastatic cases in Brazil and was not associated with the incidence of metastases. ${ }^{28}$ Abbas et al in Germany obtained different results, showing a significant correlation between PD-L1 expression and the presentation of positive PD-L1 immunoexpression, which was found in $37.8 \%$ of the metastatic group. ${ }^{29}$ The discrepancy was found to be caused by tumor heterogeneity, differences in sampling locations of tumors, examining either primary or metastatic locations, and ethnic differences. A previous systematic review of 3389 patients showed that the PD-L1 immunoexpression in patients of Asian ethnicity was lower than that of European patients. ${ }^{30}$ In addition, HIF- $\alpha$ can initiate EMT directly, without stimulating PD-L1, depending on the external factors contributing to ccRCC, including sterol regulatory elementbinding protein-1c (SREBP-1c). ${ }^{26,31-34}$ PD-L1 immunoexpression was low as PD-L1 mRNA is a strong target of miR497-5p, meaning that PD-L1 mRNA is degraded and not expressed. ${ }^{35,36}$ Research conducted by Lopez et al found high intraheterogeneity of the ccRCC. This was evident in the difference between PD-L1 immunoexpression in multiple site sampling and single random sampling. With multiple site sampling, five positive samples were obtained, while with single random sampling all samples were negative. ${ }^{27}$

This study showed no association between COX-2 and PD-L1 immunoexpression in ccRCC, meaning that COX-2 did not affect PD-L1 immunoexpression in immune cells. Other factors that may influence PD-L1 are IFN- $\gamma$, TGF- $\beta 1$, 


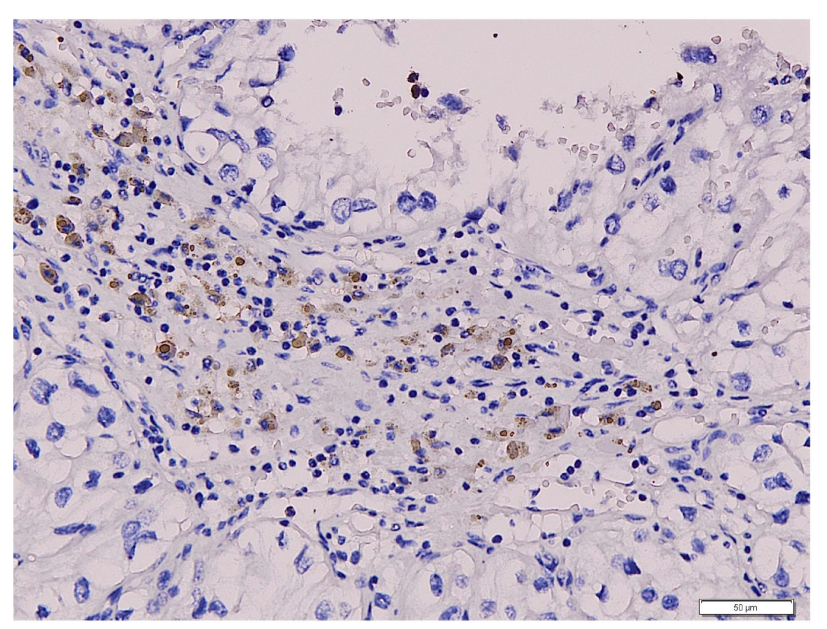

A

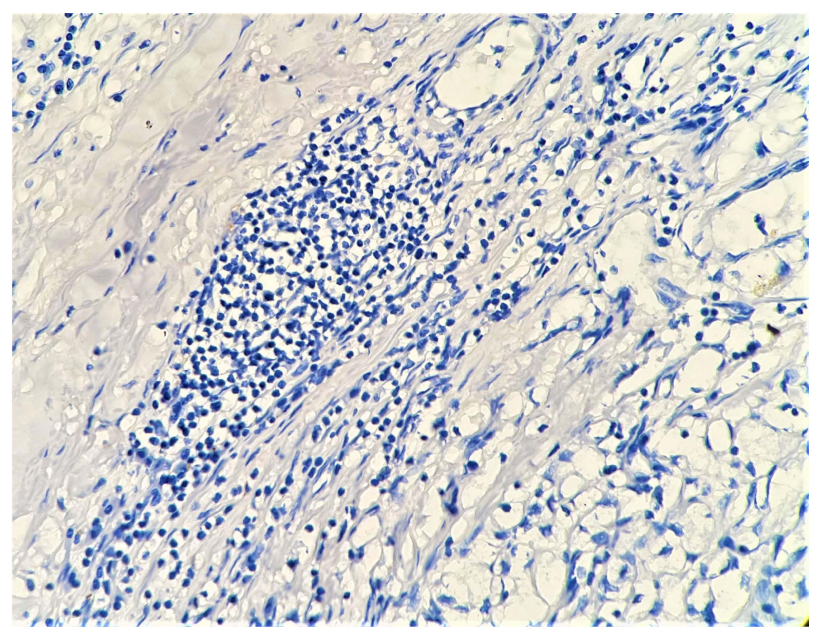

B

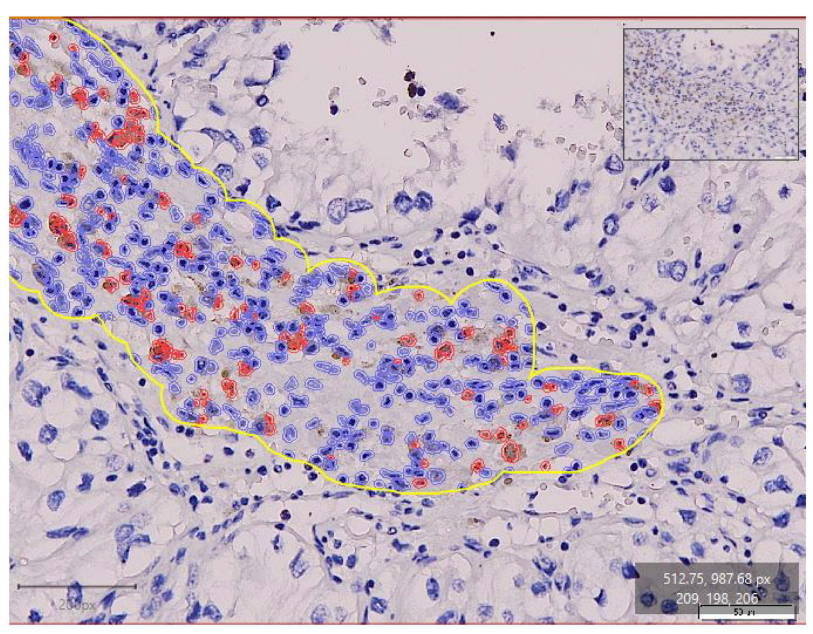

C

Figure 2 (A) Positive PD-LI immunoexpression in clear cell renal cell carcinoma (IHC;400x). (B) Negative PD-LI immunoexpression in clear cell renal cell carcinoma (IHC;400x). (C) PD-LI SPI42 scoring system on immune cells using QuPath 0.2.3 digital software (IHC;400x).

IL-17, or TNF- $\alpha$ in response to inflammatory factors released in TME during the anti-tumor immune response. ${ }^{31} \mathrm{COX}-2$ 's ability to support the process of immune evasion can be triggered automatically or by PD-L1 activation. Without PDL1 activation, the process functions using the COX-2-PGE2Prostaglandin E receptor signaling pathway, thus suppressing the function of immune cells, including dendritic cells,
Natural Killer cells, and T lymphocytes. COX-2 modulates dendritic cells by stimulating interleukin 10 (IL-10) and thus inhibiting the ability of dendritic cells to present antigens to T-lymphocytes. This automatically results in the inactivation of T-lymphocytes. This series of processes describes the role of COX-2 in tumor cell immunity pathways that can affect immunoediting in the elimination, balance, and immune

Table 2 The Association Between COX-2 Immunoexpression and Metastasis in ccRCC

\begin{tabular}{|c|c|c|c|c|}
\hline \multirow{2}{*}{} & \multicolumn{2}{|c|}{ Cases } & \multirow{2}{*}{ P-value } & \multirow{2}{*}{ POR (95\% CI) } \\
\cline { 2 - 4 } & Non-Metastatic ccRCC Group n=19 & Metastatic ccRCC Group n=2 I & \\
\hline COX-2 & $12(63.2 \%)$ & $3(14.3 \%)$ & \multirow{2}{*}{$0.001 *$} & $10.286(2.211-47.842)$ \\
Low (<10\%) & $7(36.8 \%)$ & $18(85.7 \%)$ & \\
High ( $\geq 10 \%)$ & & & \\
\hline
\end{tabular}

Note: *Chi-Square Test, $(p$-value significant $<0.05)$.

Abbreviations: POR, Prevalence Odds Ratio; ccRCC, Clear Cell Renal Cell Carcinoma; COX-2, Cyclooxygenase-2. 
Table 3 The Association Between PD-LI Immunoexpression and Metastasis in ccRCC

\begin{tabular}{|l|c|c|}
\hline & \multicolumn{3}{|c|}{ Cases } & \multirow{2}{*}{ p-value } \\
\cline { 2 - 4 } & Non-Metastatic ccRCC Group n=19 n (\%) & Metastatic ccRCC Group n=2 I n (\%) \\
\hline PD-LI & $18(94.7 \%)$ & $18(85.7)$ \\
Negative (<1\%) & $1(5.3 \%)$ & $3(14.3)$ \\
Positive ( $\geq 1 \%)$ & & 0.607 \\
\hline
\end{tabular}

Note: Fischer's exact Test ( $p$-value significant $<0.05)$.

Table 4 Association Between COX-2 and PD-LI in ccRCC

\begin{tabular}{|c|c|c|c|}
\hline \multirow{2}{*}{} & \multicolumn{2}{|c|}{ PD-LI } & \multirow{2}{*}{ P-value } \\
\cline { 2 - 3 } & Negative (<1\%) & Positive ( $\geq 1 \%)$ & \\
\hline COX-2 & & & 0.278 \\
Low (<10\%) & $15(41.7 \%)$ & $0(0 \%)$ & \\
High ( $\geq 10 \%)$ & $21(58.3 \%)$ & $4(100 \%)$ & \\
\hline
\end{tabular}

Note: Fischer's exact test ( $p$-value significant <0.05).

Abbreviations: ccRCC, Clear Cell Renal Cell Carcinoma; COX-2, Cyclooxygenase-2; PD-LI, Programmed Death Ligand-I.

escape phases, which play a role in metastasis. Immune escape results in the immune system being unable to recognize tumor cells, meaning the immune system can form supportive TME, making it easier for tumor cells to metastasize. ${ }^{6}$

This study has several limitations, including the assessment of expression using only immunohistochemistry, lack of comparison between metastatic sites, and use of only single random sampling. The authors recommend more comprehensive studies with a larger sample size taking a cohort analysis approach by using PCR gene expression measurements, taking tumor samples from multiple sites or multiple site sampling, and comparing primary and metastatic sites to address tumor heterogeneity.

\section{Conclusion}

In conclusion, high COX-2 immunoexpression is associated clinically with metastatic ccRCC, but not PD-L1 immunoexpression. There is no association between COX2 immunoexpression and PD-L1. This study proves that inflammatory factors play a role in metastasis and can be used as a theoretical basis for utilizing pathogenesisrelated inflammation to develop COX-2 inhibitors as a form of supportive therapy in the future.

\section{Abbreviations}

ccRCC, clear cell renal cell carcinoma; COX-2, cyclooxygenase-2; ECM, extracellular matrix; HIF-1 $\alpha$, hypoxiainducible factor-1 $\alpha$; IL-10, interleukin-10; ISUP,
International Society of Urological Pathology; mTOR, mammalian target of rapamycin; PD-L1, programmed death-ligand-1; STAT 3, signal transducer and activator of transcription; TME, tumor microenvironment; TNF, tumor necrosis factor; VHL, Von-Hippel Lindau.

\section{Acknowledgments}

This work was funded by an internal grant from Universitas Padjadjaran (1959/UN6.3.1/PT.00/2021). Upon completion of this paper, we would like to express our sincere gratitude to all professional statisticians, proofreaders, and laboratory technicians for supporting and assisting us during the research process.

\section{Disclosure}

The authors declare that there were no conflicts of interest in the production of this paper.

\section{References}

1. Luo L, Liang Y, Ding X, Ma X, Zhang G, Sun L. Significance of cyclooxygenase-2, prostaglandin $\mathrm{E} 2$ and $\mathrm{CD} 133$ levels in sunitinib-resistant renal cell carcinoma. Oncol Lett. 2019;18 (2):1442-1450. PMID: 31423209. doi:10.3892/ol.2019.10442

2. Moch H, Amin M, Argani P, Cheville J, Delahunt B, Martoni G. Renal cell tumor. in: Moch H, Humprey P, Ulbright T, Reuter V, editors. WHO Classification of Tumours of the Urinary System and Male Genital Organs. 4th ed. Lyon: International Agency for Research on Cancer; 2016:11-42.

3. Liu S, Han L, Wang X, et al. Nephroblastoma overexpressed gene (NOV) enhances RCC cell motility through upregulation of ICAM-1 and COX-2 expression via Akt pathway. Int J Clin Exp Pathol. 2015;8 (2):1302-1311. PMID: 25973014.

4. Chevez A, Bukowski J, Finke J. The role of inflammation in kidney cancer. in: Aggarwal B, editor. Inflammation and Cancer. Basel: Springer; 2014:197-221.

5. Shi J, Wang K, Xiong Z, et al. Impact of inflammation and immunotherapy in renal cell carcinoma. Oncol Lett. 2020;20(5):272. PMID: 33014151. doi:10.3892/ol.2020.12135

6. Goradel N, Najafi M, Salehi E, Farhood B, Mortezaee K. Cyclooxygenase-2 in cancer: a review. J Cell Physiol. 2019;234 (5):5683-5699. PMID: 30341914. doi:10.1002/jcp.27411

7. Yang S, Gao Q, Jiang W. Relationship between tumour angiogenesis and expression of cyclo-oxygenase-2 and vascular endothelial growth factor-A in human renal cell carcinoma. $J$ Int Med Res. 2015;43 (1):110-117. PMID: 25488950. doi:10.1177/0300060514545799 
8. Prima V, Kaliberova L, Kaliberov S, Curiel D, Kusmartsev S. COX2/ mPGES1/PGE2 pathway regulates PD-L1 expression in tumor associated macrophages and myeloid-derived supressor cells. PNAS. 2017;114(5):1117-1122. doi:10.1073/pnas.1612920114

9. Putri L, Riani F, Dewayani B, Zamalek N, Suryawathy B. The correlation of programmed death ligand 1 immunoexpression with neutrophil-to-lymphocyte ratio in diffuse large B-cell lymphoma. Pathology. 2021;53(1):S58. doi:10.1016/j.pathol.2021.05.084

10. Lin H, Wei S, Hurt EM, et al. Host expression of PD-L1 determines efficacy of PD-L1 pathway blockade-mediated tumor regression. J Clin Invest. 2018;128(2):805-815. PMID: 29337305. doi:10.1172/ JCI196113

11. Makhov P, Joshi S, Ghatalia P, Kutikov A, Uzzo R, Kolenko V. Resistence to systemic therapies in clear cell renal cell carcinoma: mechanisms and management strategies. Mol Cancer Ther. 2018;17 (7):1355-1364. PMID: 29967214. doi:10.1158/1535-7163.MCT-171299

12. Shaashua L, Shabat-Simon M, Haldar R, et al. Perioperative COX-2 and $\beta$-adrenergic blockade improves metastatic biomarkers in breast cancer patients in a phase-II randomized trial. Clin Cancer Res. 2017;23(16):4651-4661. PMID: 28490464. doi:10.1158/1078-0432. CCR-17-0152

13. Soto M, O'Brien E, Sibson N. Disruption of tumor-host communication by down regulation of LFA-1reduces COX-2 and e-NOS expression and inhibits brain metastasis growth. Oncotarget. 2016;7 (32):52375-52391. PMID:27447568. doi:10.18632/oncotarget.10737

14. Ikatan Ahli Urologi Indonesia. Pedoman Tata Laksana Kanker Ginjal. 2 ed. Jakarta: IAUI; 2019:1-39.

15. Botti G, Fratangelo F, Cerrone M. COX-2 expression positively correlates with PD-L1 expression in human melanoma. J Transl Med. 2017;15(1):1-12. PMID: 28231855. doi:10.1186/s12967-0171150-7

16. Liang X, Liu Y, Ran P, Tang M, Xu C, Zhu Y. Sarcomatoid renal cell carcinoma: a case report and literature review. BMC Nephrol. 2018;19(1):84. doi:10.1186/s12882-018-0884-7

17. Markosyan N, Chen EP, Evans RA, Ndong V, Vonderheide RH, Smyth EM. Mammary carcinoma cell derived cyclooxygenase 2 suppresses tumor immune surveillance by enhancing intratumoral immune checkpoint activity. Breast Cancer Res. 2013;15(5). PMID: 24004819. doi:10.1186/bcr3469

18. Bankhead P, Loughrey M, Fernandez J, et al. QuPath: open source software for digital pathology image analysis. Sci Rep. 2017;7:1-7. doi:10.1038/s41598-017-17204-5

19. Alexander L, Lopes B, Ricchetti K, Yeats K. Cross-Sectional Studies. 2 ed. UNC CH Department of Epidemiology; 2015:1-5. Available from: https://sph.unc.edu/wp-content/uploads/sites/112/2015/07/ nciph_ERIC8.pdf. Accessed July 23, 2021.

20. Gipsyianti N, Aziz A, Hernowo B, High HU. Expression of COX-2 associated with the depth of invasion on acral melanoma by increasing TGF- $\beta 1$. Clin Cosmet Investig Dermatol. 2021;14:209-216. doi: $10.2147 /$ CCID.S285564

21. Szlendak M, Sitarz R, Berbecka M, et al. Expression of cyclooxygenase-2 and mucin 1 in colorectal cancer. Mol Clin Oncol. 2020;13(5):52. doi:10.3892/mco.2020.122

Research and Reports in Urology

\section{Publish your work in this journal}

Research and Reports in Urology is an international, peer-reviewed, open access journal publishing original research, reports, editorials, reviews and commentaries on all aspects of adult and pediatric urology in the clinic and laboratory including the following topics: Pathology, pathophysiology of urological disease; Investigation and
22. Jana D, Sarkar D, Ganguly S, et al. Role of Cyclooxygenase 2 (COX-2) in prognosis of breast cancer. Indian J Surg Oncol. 2014;5 (1):59-65. PMID: 24669166. doi:10.1007/s13193-014-0290-y

23. Qiu J, Shi Z, Jiang J. Cyclooxygenase-2 in glioblastoma multiforme. Drug Discov Today. 2017;22(1):148-156. PMID: 27693715. doi:10.1016/j.drudis.2016.09.017

24. Ross C, Hunter K. Metastatic signatures - The tell-tale signs of metastasis. In: Boffetta P., Hainaut P., editors. Encyclopedia of Cancer. 3rd ed. Elsevier; Oxford, UK. 2019:426-434. doi:10.1016/ B978-0-12-801238-3.65027-4

25. Gately S, Li W. Multiple roles of COX-2 in tumor angiogenesis: a target for antiangiogenic therapy. Semin Oncol. 2004;31(2):2-11. PMID: 15179620. doi:10.1053/j.seminoncol.2004.03.040

26. Wang Y, Wang H, Zhao Q, Xia Y, Hu X, Guo J. PD-L1 induces epithelial-to-mesenchymal transition via activating SREBP-1c in renal cell carcinoma. Med Oncol. 2015;32(212):1-7. PMID: 26141060. doi:10.1007/s12032-015-0655-2

27. Lopez J, Pulido R, Cortes J, Angulo J, Lawrie C. Potential impact of PD-L1 (SP-142) immunohistochemical heterogeneity in clear cell renal cell carcinoma immunotherapy. Pathol Res Pract. 2018;214 (8):1-5. PMID: 29910061. doi:10.1016/j.prp.2018.06.003

28. Leite K, Reis S, Junior J, et al. PD-L1 expression in renal cell carcinoma clear cell type is related to unfavourable prognosis. Diagn Pathol. 2015;10:189. PMID: 26470780. doi:10.1186/s13000015-0414-x

29. Abbas M, Steffens S, Bellut M, et al. Intratumoral expression of PD-L1 in patients with clear cell carcinoma (ccRCC). Med Oncol. 2016;33(7):80. PMID:27317388. doi:10.1007/s12032-016-0794-0

30. $\mathrm{Lu} \mathrm{Y}$, Song $\mathrm{Y}, \mathrm{Xu} \mathrm{Y}$, et al. The prevalence and prognostic and clinicopathological value of PD-L1 and PD-L2 in renal cell carcinoma patients: a systemic review and meta analysis involving 3389 patients. Trans Androl Urol. 2020;9(2):367-381. PMID: 32420142. doi:10.21037/tau.2020.01.21

31. Dong P, Xiong Y, Yue J, Hanley SJB, Watari H. Tumor-intrinsic PD-L1 signaling in cancer initiation, development and treatment: beyond immune evasion. Front Oncol. 2018;8(386):1-6. PMID: 32420142. doi:10.21037/tau.2020.01.21

32. Ferronika P, Kats-Ugurlu G, Haryana SM, et al. Mutational heterogeneity between different regional tumour grades of clear cell renal cell carcinoma. Exp Mol Pathol. 2020;115(104431):1-10. PMID: 32259515. doi:10.1016/j.yexmp.2020.104431

33. Jilaveanu L, Shuch B, Zito C, et al. PD-L1 expression in clear cell renal cell carcinoma: an analysis of nephrectomy and sites of metastases. J Cancer. 2014;5:166-172. doi:10.7150/jca.8167

34. Aurilio G, Piva F, Santoni M, et al. The role of obesity in renal cell carcinoma patients: clinical-pathological implications. Int $\mathrm{J} \mathrm{Mol} \mathrm{Sci}$. 2019;20(22):5683. PMID: 31766196. doi:10.3390/ijms20225683

35. Wang Y, Wang H, Yao H, Li C, Fang J, Xu J. Regulation of PD-L1: emerging routes for targeting tumor immune evasion. Front Pharmacol. 2018;9(536):1-12.

36. Qu F, Ye J, Pan X, et al. MicroRNA-497-5p down-regulation increases PD-L1 expression in clear cell renal cell carcinoma. J Drug Target. 2019;27(1):67-74. PMID:30183478. doi:10.1080/ 1061186X.2018.1479755

treatment of urological disease; Pharmacology of drugs used for the treatment of urological disease. The manuscript management system is completely online and includes a very quick and fair peer-review system, which is all easy to use. Visit http://www.dovepress.com/ testimonials.php to read real quotes from published authors. 